\title{
Furfural and 5-(Hydroxymethyl) furfural Tolerance Candida strains in Bioethanol Fermentation
}

\author{
Ahmad Thontowi ${ }^{1}$, Urip Perwitasari ${ }^{1}$, Lutfi Nia Kholida ${ }^{1}$, Atit Kanti ${ }^{2}$, Yopi ${ }^{3}$, and Bambang \\ Prasetya $^{3}$ \\ ${ }^{1}$ Research Center for Biotechnology, Indonesian Institute of Sciences (LIPI), Indonesia \\ ${ }^{2}$ Research Center for Biology, Indonesian Institute of Sciences (LIPI), Indonesia \\ ${ }^{3}$ National Standardization Agency (BSN), Indonesia
}

\begin{abstract}
The toxic fermentation inhibitors in lignocellulosic hydrolysates pose significant problems for the production of second-generation biofuels and biochemicals. Among these inhibitors, 5-(hydroxymethyl)furfural (HMF) and furfural are specifically well known. This study investigated the furfural and 5-HMF tolerance in Candida strains, which could be used for the development of advanced generation bioethanol processes. The 10 isolates of Candida were selected based on the cell growth and bioethanol production on YPD medium containing several concentrations of furfural and 5-HMF by using spectrophotometer and HPLC. Candida parapsilosis Y80 could grow and produce bioethanol in the medium that contains furfural and 5-HMF with a concentration of 60 $\mathrm{mM}$ and $40 \mathrm{mM}$, respectively. Based on the results, C. parapsilosis Y80 has potential activity in the development of bioethanol fermentation.
\end{abstract}

Keywords: Furfural, 5-Hydroxymethylfurfural, Candida, bioethanol

*Corresponding author:

Cibinong Science Center, Jl. Raya Bogor Km. 46, Cibinong 16911, Indonesia

Tel. +62-21-8754587, Fax. +62-21-87754588

E-mail. athontowi777@gmail.com

\section{Introduction}

The utilization of raw materials from lignocellulosic biomass for bioethanol production requires a pre-treatment process (Ahmad et al., 2017; Chen et al., 2017; Kumar \& Sharma 2017; Baruah et al., 2018). This step-change the biomass polymer structure to sugar monomer and enhanced the efficiency of hydrolysis by enzymes (Satari et al., 2019). Lignocellulose pretreatments produced various small compounds, including furan derivates, organic acids, and phenolic compounds (Jonsson et al., 2016; Sarks et al., 2018). These compounds include salt (Zacky et al., 2017), weak acids (acetic, formic, levulinic, coumaric, etc.), furyl compounds (furfural or hydroxymethylfurfural (HMF)) or phenolic compounds (vanillin or vanillic acid) (Zhang et al., 2013; Steinbach et al., 2017). The hydrothermal method $\left(130{ }^{\circ} \mathrm{C}\right.$ or above $)$ generates between $6-90 \mathrm{mM}$ acetic acid depending on the temperature chosen with similar concurrent increases in formic acid, furfural, and HMF (Greetham et al., 2014). The presence of inhibitory compounds has been shown to reduce fermentation efficiencies, for example, the presence of 0.5 $\mathrm{mM}$ furfural has been reported to reduce ethanol production and at $4 \mathrm{mM}$ (Greetham et al., 2014). The presence of $20 \mathrm{mM}$ acetic acid has been shown to induce ethanol production, however, higher concentrations can inhibit ethanol production. These compounds are strong inhibitors for enzymes and fermenting microorganisms. Furfural and 5(hydroxymethyl)furfural (5-HMF) are considered as the major inhibitors because both are high in concentration and strong in inhibition strength to ethanol fermenting strains (Iwaki et al., 2013; Jöansson \& Martin, 2014; Kahar et al., 2017). They are formed as hexose and pentose dehydrated products, respectively, and have been shown to inhibit cell growth, decrease ethanol productivity, induce DNA damage and inhibit some enzymes in glycolysis, thus posing serious challenges to the feasibility of ethanol production of lignocellulose (Modig et al., 2002; Allen et al., 2010). 
The development of stress-tolerant ethanologenic yeast is one of the significant challenges for cost-competitive bioethanol production (Kahar et al., 2017). Many yeasts were reported could grow on the medium containing inhibitor by adaptation (Heer and Sauer, 2008; Liu et al., 2004; Parawira and Tekere, 2011). Some genetic traits also proposed for the improvement of the yeast strain mainly through gene overexpression in the laboratory (Klein et al., 1999). However, most of the studies investigated the strains tolerance in the medium containing single inhibitor or simple mixtures of furfural, 5HMF and acetic acid (Gorsich et al., 2006; Park et al., 2011).

In the bioethanol industry, yeast strains play an important role in fermentation. Stronger bioethanol-producing yeasts are needed to overcome these process constraints and hence, there is a need to increase understanding of physiological responses to HMF and furfural to increase strain resistance. Some reports also showed that this strain was tolerant to furfural and 5-HMF (Iwaki et al., 2013; Ask et al., 2013; Ohta et al., 2016; Narayanan et al., 2017; Lia et al., 2017; Unrean et al., 2018; Mertensa et al., 2018).

However, the inhibitors-tolerant and bioethanol-producing non-Saccharomyces yeast strains was reported to be relatively less. For this reason, it is necessary to obtain information regarding non-Saccharomyces inhibitors tolerant strains for bioethanol fermentation. The purposes of this study were to screen furfural and 5-HMF tolerant Candida strains and to characterize the degradation process of these compounds.

\section{Materials and Methods}

\section{Yeast strain and medium}

In this study, we used 10 strains of the genus Candida yeast from 7 different species. The Candida yeasts were obtained from Indonesia Culture Collection (InaCC), Indonesian Institute of Sciences (LIPI).

\section{Medium}

For routine subculturing and maintenance, yeast strains were grown on Yeast Peptone Glucose (YPD) agar containing $10 \mathrm{~g} / \mathrm{L}$ yeast extract (Difco), $20 \mathrm{~g} / \mathrm{L}$ bacto peptone (Difco), $20 \mathrm{~g} / \mathrm{L}$ glucose (Merck), and $15 \mathrm{~g} / \mathrm{L}$ agar
(Difco). For pre-culture, one single colony of strain was inoculated from the YPD plate into $12 \mathrm{~mL}$ YPD liquid medium in $100 \mathrm{~mL}$ Erlenmeyer flask. The culture was incubated overnight at $30^{\circ} \mathrm{C}$ and $150 \mathrm{rpm}$.

\section{Yeasts Screening in various concentrations of furfural and 5-HMF}

The ten strains from the Candida genus were screened based on cell growth and bioethanol production in various concentrations of furfural and 5-HMF. The yeast strains were cultured in YPD liquid medium containing glucose $20 \mathrm{~g} / \mathrm{L}$ to obtain the cell biomass as a pre-culture. The fermentation was conducted at $400 \mathrm{rpm}$ with $30{ }^{\circ} \mathrm{C}$ overnight in deep well. The pre-culture of biomass yeasts were cultured in Yeast Nitrogen Base (YNB) without amino Acids and Ammonium Sulfate (Difco) medium including various concentration furfural (Nacalai Tesque, Japan) $(0,20,40,60,80$, and $100 \mathrm{mM}$ ) and 5-HMF (Nacalai Tesque, Japan) $(0,20,40,60,80$, and $100 \mathrm{mM})$. The fermentation was conducted at $1400 \mathrm{rpm}$ with $30{ }^{\circ} \mathrm{C}$ for $24 \mathrm{~h}$ in deep well. All experiments were performed in triplicate.

\section{Fermentation of InaCCY80 strain in medium containing furfural and 5-HMF}

InaCCY80 strain was selected as tolerant yeast in this study based on growth and bioethanol production in various medium containing furfural and 5-HMF. The purpose of this step was to obtain the information of InaCCY80 fermentation in medium containing furfural or 5-HMF. The yeast strain was cultured in YPD medium to obtain cell biomass as a pre-culture. The fermentation was conducted at $150 \mathrm{rpm}$ with $30{ }^{\circ} \mathrm{C}$ for overnight in the flask. The main culture of InaCCY80 biomass was cultured in YNB medium containing glucose $20 \mathrm{~g} / \mathrm{L}$ and $40 \mathrm{mM}$ furfural, and glucose $20 \mathrm{~g} / \mathrm{L}$ including $20 \mathrm{mM}$ 5-HMF. The extended lag phase corresponded to the increase in the concentration of furfural, and the cells lost their survival ability in the medium containing 60 and $80 \mathrm{mM}$ (Fig. 1A). According to these results, we decided to use the YNB medium containing $40 \mathrm{mM}$ furfural for further analysis, because the InaCCY 80 strain could grow and ferment the sugars under such stress conditions. The fermentations were conducted at $150 \mathrm{rpm}$ with $30{ }^{\circ} \mathrm{C}$ for $30 \mathrm{~h}$ in 
the flask. All experiments were performed in triplicate.

\section{Effect of furfural and 5-HMF mixtures on Fermentation of InaCCY80 strain}

The purpose of this step is to get knowledge regarding the effect of cell growth and bioethanol production upon the stress challenge in the presence of furfural and 5HMF mixtures. The previous results showed that the InaCCY80 strain was able to grow and produce ethanol in the medium containing furfural and 5-HMF at certain concentrations. However, the cell strain growth was carried out in a medium containing furfural and 5HMF separately. For this reason, it was necessary to test the growth of the InaCCY80 strain in a medium containing the mixture of furfural and 5-HMF.

InaCCY80 yeast strain were grown in the YNB medium as a control, and the YNB medium containing a mixture of furfural and 5-HMF in different concentrations (Table 1). YNBi-1 medium contained furfural and 5HMF with fewer concentration than in the YNBi-2 medium. InaCCY80 strain was cultured in the YPD medium to obtained cell biomass as a pre-culture. The fermentation was conducted overnight at $150 \mathrm{rpm}$ with $30{ }^{\circ} \mathrm{C}$ in the flask. The pre-culture of InaCCY80 biomass was cultured in YNB medium containing glucose $50 \mathrm{~g} / \mathrm{L}$, furfural, and 5HMF mixture with the variation of concentrations based on the previous results (Table 1). The fermentation was conducted at $150 \mathrm{rpm}$ with $30{ }^{\circ} \mathrm{C}$ for $30 \mathrm{~h}$ in the flask. All experiments were performed in triplicate.

Table 1. Composition of furfural and 5-HMF compounds in different synthetic media

\begin{tabular}{lcc}
\hline Medium & $\begin{array}{c}\text { Furfural } \\
(\mathrm{mM})\end{array}$ & $\begin{array}{c}5-\mathrm{HMF} \\
(\mathrm{mM})\end{array}$ \\
\hline YNB (control) & 0 & 0 \\
YNBi-1 & 12 & 2 \\
YNBi-2 & 30 & 5 \\
\hline
\end{tabular}

\section{Fermentation product analysis}

The culture cell growth was measured using the dry cell weight. Cells were freeze-dried prior to weighing using freeze dryer Alpha 1-2 LD plus (Germany). The fermentation products (glucose consumption and ethanol production) were analyzed using High-
Performance Liquid Chromatography (HPLC) (Shimadzu LC-20AB, Japan). The analytes were detected using refractive index detector (RID) and Aminex HPX-87H column from Bio-Rad as a stationary phase, with the condition as follows, the flow rate of 0.6 $\mathrm{mL} / \mathrm{min}$, oven temperature for the column of $60{ }^{\circ} \mathrm{C}$, injection volume of $20 \mu \mathrm{L}$, elution time of 30 minutes, and eluent of $5 \mathrm{mM} \mathrm{H}_{2} \mathrm{SO}_{4}$. The calculation of ethanol yield referred to the Nutawan method (Nutawan et al. 2010).

\section{Results}

\section{Screening of BTCC yeasts in furfural and 5- HMF}

The growth of ten strains in YNB medium containing furfural showed that the isolates were able to grow at various concentrations (Table 2). In general, this Candida strain produced bioethanol with a concentration of 0 $5 \mathrm{~g} / \mathrm{L}$. However, only the strain InaCCY80 produced bioethanol in furfural to a concentration of $60 \mathrm{mM}$. The volume of bioethanol produced ranged from $6-10 \mathrm{~g} / \mathrm{L}$.

Table 2. The cell growth and ethanol production of several yeast strains after incubation in medium YNB containing furfural with different concentrations

\begin{tabular}{lcccccccccccc}
\hline Strain Code & \multicolumn{4}{c}{ Cell (OD 600 nm) } & \multicolumn{4}{c}{ Ethanol (g/L) } \\
& \multicolumn{4}{c}{ Furfural (mM) } & \multicolumn{4}{c}{ Furfural (mM) } \\
& 0 & 20 & 40 & 60 & 80 & 100 & 0 & 20 & 40 & 60 & 80 & 100
\end{tabular}

$$
\begin{array}{r}
\text { C. orthopsilosis InaCCY7 } \\
\text { C. orthopsilosis InaCCY10 } \\
\text { C. viswanathii InaCCY54 } \\
\text { C. viswanathii InaCCY55 } \\
\text { C. glabrata InaCCY68 } \\
\text { C. wickerhamii InaCCY74 } \\
\text { C. jaroonii InaCCY78 } \\
\text { C. parapsilosis InaCCY80 } \\
\text { C. carpophila InaCCY89 } \\
\text { C. carpophila InaCCY90 }
\end{array}
$$

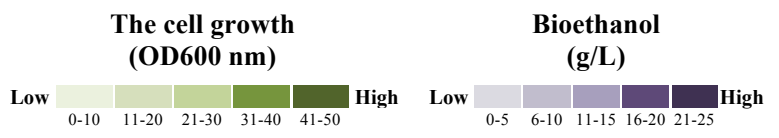

The growth of ten strains in YNB medium containing 5-HMF showed that the isolates were able to grow at various concentrations 
(Table 3). In general, this Candida strain produced bioethanol with concentration of 0-5 $\mathrm{g} / \mathrm{L}$. However, strain InaCCY80, InaCCY89, and InaCC90 still produced bioethanol in medium with the 5-HMF concentration up to $20 \mathrm{mM}$. InaCCY80, in particular, could produce bioethanol at $40 \mathrm{mM}$, ranged from 6$10 \mathrm{~g} / \mathrm{L}$.

Table 3. The cell growth and ethanol production of several yeast strains after incubation in medium YNB containing 5-HMF with different concentrations

\begin{tabular}{|c|c|c|c|c|c|}
\hline \multirow[t]{2}{*}{ Strain Code } & \multicolumn{2}{|c|}{$\begin{array}{l}\text { Cell (OD } 600 \mathrm{~nm}) \\
5-\mathrm{HMF}(\mathrm{mM})\end{array}$} & \multicolumn{3}{|c|}{$\begin{array}{l}\text { Ethanol (g/L) } \\
\text { 5-HMF (mM) }\end{array}$} \\
\hline & $0 \quad 20$ & $40 \quad 60$ & $0 \quad 20$ & 40 & 60 \\
\hline \multicolumn{6}{|l|}{ C. orthopsilosis InaCCY7 } \\
\hline \multicolumn{6}{|l|}{ C. orthopsilosis InaCCY10 } \\
\hline \multicolumn{6}{|l|}{ C. viswanathii InaCCY54 } \\
\hline \multicolumn{6}{|l|}{ C. viswanathii InaCCY55 } \\
\hline \multicolumn{6}{|l|}{ C. glabrata InaCCY 68} \\
\hline \multicolumn{6}{|l|}{ C. wickerhamii InaCCY74 } \\
\hline \multicolumn{6}{|l|}{ C. jaroonii InaCCY78 } \\
\hline \multicolumn{6}{|l|}{ C. parapsilosis InaCCY80 } \\
\hline \multicolumn{6}{|l|}{ C. carpophila InaCCY89 } \\
\hline \multicolumn{6}{|l|}{ C. carpophila InaCCY90 } \\
\hline \multicolumn{3}{|l|}{$\begin{array}{l}\text { The cell growth } \\
\text { (OD600 nm) }\end{array}$} & \multicolumn{3}{|c|}{$\begin{array}{c}\text { Bioethanol } \\
(\mathrm{g} / \mathrm{L})\end{array}$} \\
\hline \multicolumn{6}{|l|}{\begin{tabular}{ll|l|l|l|l|} 
Low & $0-10$ & $11-20$ & $21-30$ & $31-40$ & $41-50$
\end{tabular}} \\
\hline $\begin{array}{l}\text { InaCCY80 strain } \\
\text { medium containing } \\
\text { concentrations }(0,40 \text {, } \\
\text { HMF }(0,40 \text {, and } 60 \\
\text { inhibitors effect on its } \\
\text { profiles. }\end{array}$ & $\begin{array}{l}\text { was } \\
\text { furf } \\
60 \\
\mathrm{mM} \\
\text { grow }\end{array}$ & $\begin{array}{l}\text { grow } \\
\text { fural } \\
\text { and } 80 \\
\text { ) to in } \\
\text { th and }\end{array}$ & $\begin{array}{l}\mathrm{vn} \text { in } \\
\text { in di } \\
0 \mathrm{mM}) \\
\text { fvestig } \\
\text { ferme }\end{array}$ & $\begin{array}{r}Y \\
\text { iffe } \\
\text { o } \\
\text { ate } \\
\text { nta }\end{array}$ & $\begin{array}{l}\text { NB } \\
\text { rent } \\
\text { r 5- } \\
\text { the } \\
\text { tion }\end{array}$ \\
\hline
\end{tabular}

\section{Metabolites profile of $C$. parapsilosis InaCCY80 in furfural}

The strain grown in YNB medium without furfural $(0 \mathrm{mM})$ was used as control. The growth was stopped as the cells deceased. Cell survival was observed in the medium containing a comparatively low amount of furfural $(60$ and $80 \mathrm{mM})$ with a shorter lag phase compared to that in the full strength YNB medium.

Fig. 1B shows that glucose consumption was delayed as the furfural concentration increased. The rate of glucose consumption varied depending on the level of furfural in the medium. As shown in Fig. 1B, a higher concentration of furfural prolonged the lag phase during the fermentation process. On the medium containing $40 \mathrm{mM}$, the strain readily consumed the glucose when the fermentation was started. The glucose was rapidly used just after $9 \mathrm{~h}$, and the remaining $7 \mathrm{~g} / \mathrm{L}$ was consumed at $30 \mathrm{~h}$. In the medium YNB containing 60 and $80 \mathrm{mM}$, the strain consumed the glucose around 4-6 g/L.

On the medium containing $40 \mathrm{mM}$, the lag phase was up to $9 \mathrm{~h}$, and then the strain started to consume the glucose for cell growth, and after 24 hours, the remaining glucose was 7 $\mathrm{g} / \mathrm{L}$. On the medium YNB containing 60 and $80 \mathrm{mM}$, the strain grew lower than $40 \mathrm{mM}$ furfural, and started to utilize glucose at $9 \mathrm{~h}$, and assimilated the glucose of $13-17 \mathrm{~g} / \mathrm{L}$ at 30 $\mathrm{h}$. The ethanol production was growthdependent as it increased just after the glucose consumption started. InaCCY80 strain could produce ethanol up to $3.8 \mathrm{~g} / \mathrm{L}$ in the $\mathrm{YNB}$ medium containing $40 \mathrm{mM}$ furfural. In another result, 0.8 and $1.6 \mathrm{~g} / \mathrm{L}$ ethanol was produced at 60 and $80 \mathrm{mM}$ of furfural (Fig. 1C).

From the profiles of cell growth and bioethanol production, the cells survived due to the succesful detoxification of 40 and 60 $\mathrm{mM}$ furfural (Fig. 1D). The concentration of furfural declined during the fermentation. In the YNB medium containing 60 and $80 \mathrm{mM}$ furfural, the cells decreased as a result of incapability for survival, as shown from the inhibitor profiles that the detoxification of furfural failed, where furfural remained 72 and $92 \%$ of initial concentration at the end of incubation (Fig. 1D).

\section{Metabolites profile of $C$. parapsilosis InaCCY80 in 5-HMF}

The cell growth of the InaCCY 80 strain in a medium containing 5-HMF was lower than in a medium without 5-HMF (Figure 2B). The lag phase of the InaCCY80 cell occurred at the 9 hour, but the growth toward the stationary phase was relatively low in the YNB medium containing 40 and $60 \mathrm{mM} \mathrm{5-HMF}$. Figure 2B shows that glucose consumption by the InaCCY80 strain containing 40 and $60 \mathrm{mM} \mathrm{5-}$ HMF was lower than in the YNB medium without the presence of this compound. In a medium without 5-HMF, glucose was consumed by the InaCCY 80 strain until it was remained at the 30 hour after fermentation. However, in a medium containing 5-HMF, at the 30 hour after incubation glucose remained 
up to $63.5 \%$ and $86 \%$ respectively at concentrations of 40 and $605-\mathrm{HMF}$.

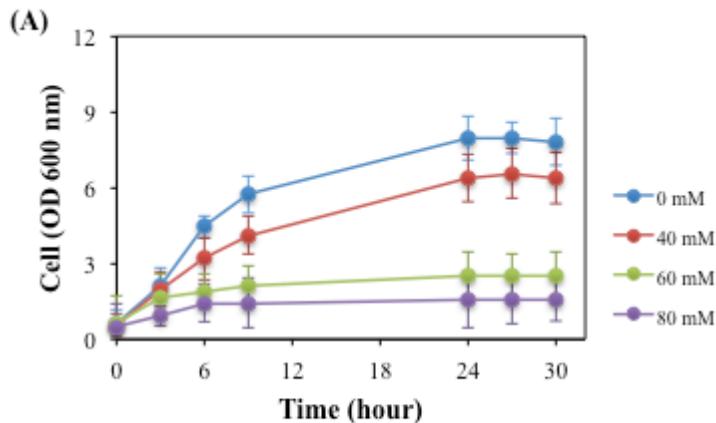

(B)

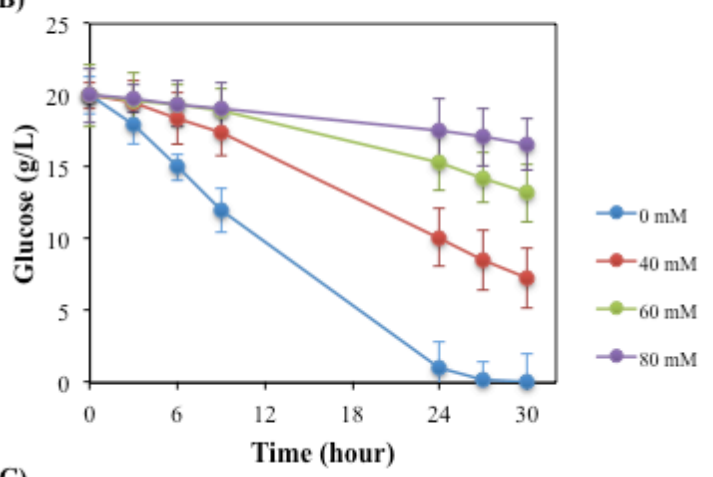

(C)

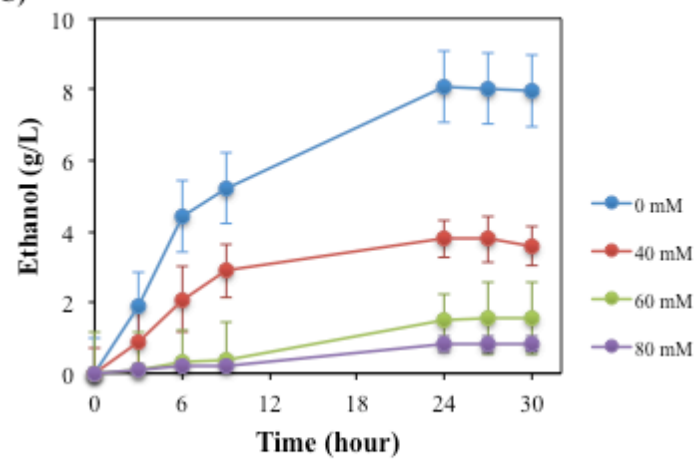

(D)

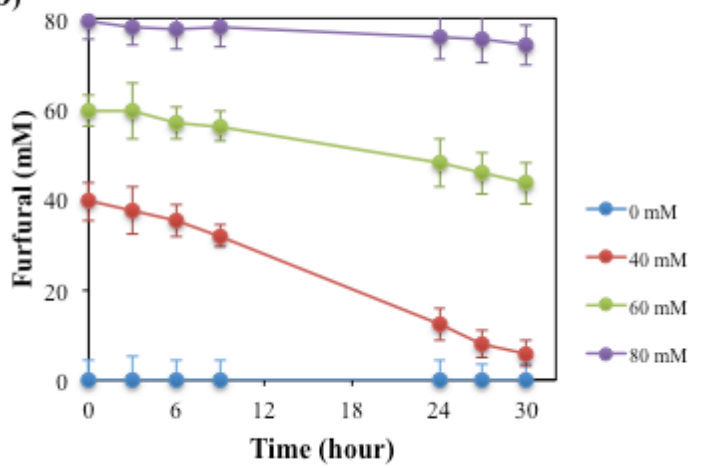

Figure 1. Metabolites profile (A) cell growth, (B) glucose consumption, (C) ethanol, and (D) furfural degradation of $C$. parapsilosis InaCCY80 in medium containing furfural.

Glucose consumption in medium containing 5-HMF had an impact on ethanol production by the InaCCY 80 strain. In the medium conditions without 5-HMF, the InaCCY80 strain was capable to produce about $6 \mathrm{~g} / \mathrm{L}$ ethanol. However, ethanol was produced around 2.6 and $1.2 \mathrm{~g} / \mathrm{L}$ in the medium containing 40 and $60 \mathrm{mM}$ 5-HMF (Figure 2C).

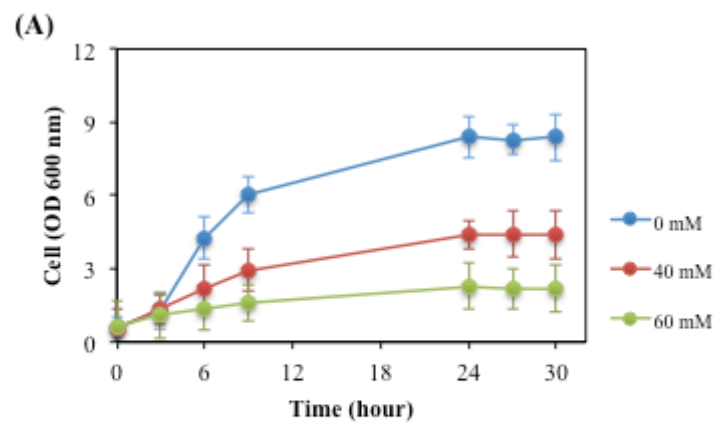

(B)
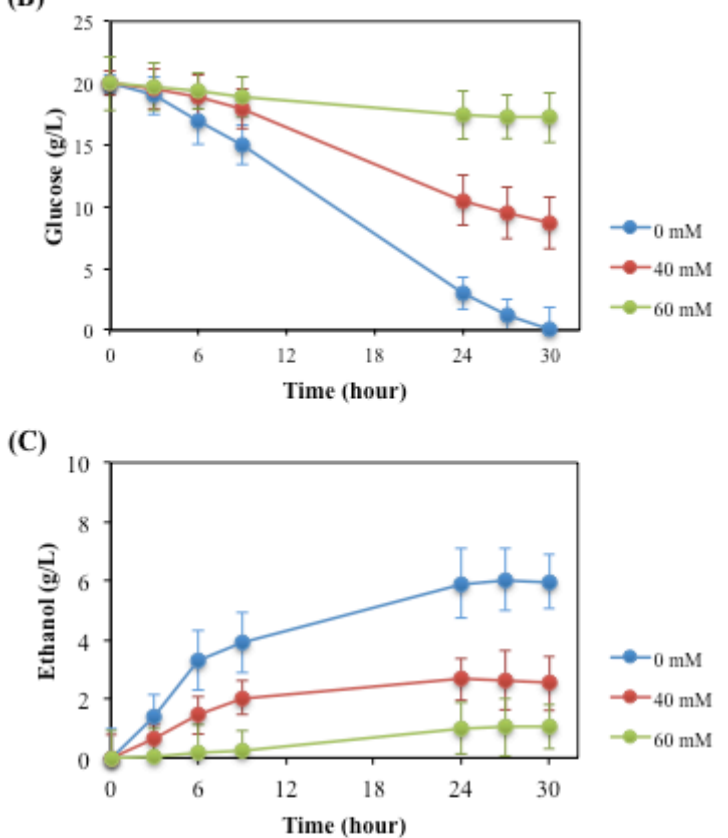

(D)

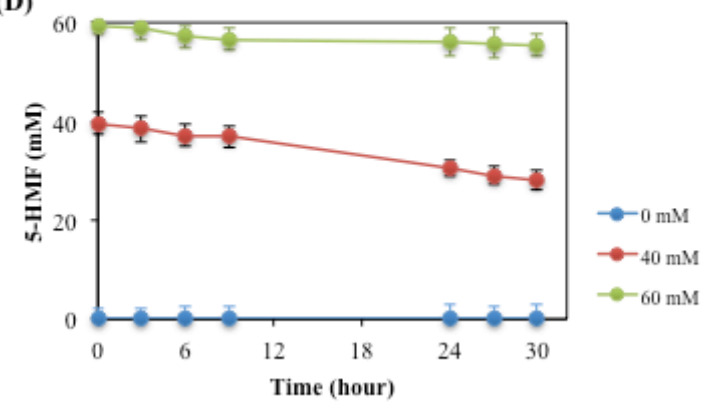

Figure 2. Metabolites profile (A) cell growth, (B) glucose consumption, (C) ethanol, and (D) 5-HMF degradation of $C$. parapsilosis InaCCY80 in medium containing 5-HMF.

Figure 2D shows that the degradation of 5HMF by InaCC Y 80 strain was relatively low 
at a concentration of $40 \mathrm{mM}$, which was about $30 \%$ of the initial concentration. Even at the concentration of $60 \mathrm{mM}$, about $5 \%$ of 5 -HMF was degraded. The higher the 5-HMF concentration in the medium, the lower its degradation ability by InaCCY 80 strain.

\section{Effect of Furfural and 5-HMF mixture to C. parapsilosis InaCCY80}

Figure 3B shows the growth of the InaCCY80 strain in the YNBi-1 medium. In this medium, the InaCCY80 strain was able to grow, although it was relatively lower than its growth in the YNB medium without the presence of furfural and 5-HMF. This yeast strain consumed all glucose after 24 hours fermentation. However, the speed of consumption was relatively slower than in the medium without the two inhibitor compounds (YNB medium). Likewise, its ability to produce bioethanol was relatively lower when compared to medium without a mixture of furfural and 5-HMF. In this medium, bioethanol was produced around $14 \mathrm{~g} / \mathrm{L}$, while in medium without furfural and 5-HMF bioethanol was produced around $17 \mathrm{~g} / \mathrm{L}$. As for the furfural and 5-HMF compounds, they were consumed after 24-h incubation. These results indicated that the InaCCY80 strain was able to carry out its metabolism well in the presence of a mixture of $12 \mathrm{mM}$ furfural compound and $2 \mathrm{mM} 5$-HMF.

Different results were shown when the InaCCY80 strain was grown in YNBi-2 media. The YNBi-2 medium contained $30 \mathrm{mM}$ furfural and $5 \mathrm{mM} 5-\mathrm{HMF}$. The content of inhibitor compounds in the YNBi-2 medium is higher than YNBi-1. Figure 3C shows that the InaCCY80 strain was able to grow relatively low compared to YNB and YNBi-1. This strain was only able to consume glucose by $31 \%$ after 24 hours of incubation. After that, glucose was relatively unconsumed by the InaCCY80 strain. This shows that the InaCCY80 strain in YNBi-2 was inhibited by a mixture of $30 \mathrm{mM}$ furfural and $5 \mathrm{mM} 5-\mathrm{HMF}$. This condition was followed by a decrease in bioethanol production compared to when the InaCCY80 strain was grown in the YNBi-1 medium. In the YNBi-2 medium, the highest bioethanol production was obtained at $8 \mathrm{~g} / \mathrm{L}$ at 24 hours after incubation. This result was lower than when the InaCCY80 strain was grown in the YNB and YNBi-1 medium (Figures $3 \mathrm{~A}$ and $3 \mathrm{~B}$ ). Furfural and 5-HMF degradation by InaCCY80 strains ranged from 20 to $40 \%$. This shows that the higher furfural and 5-HMF concentrations, the metabolism of the InaCCY80 strain was more inhibited.
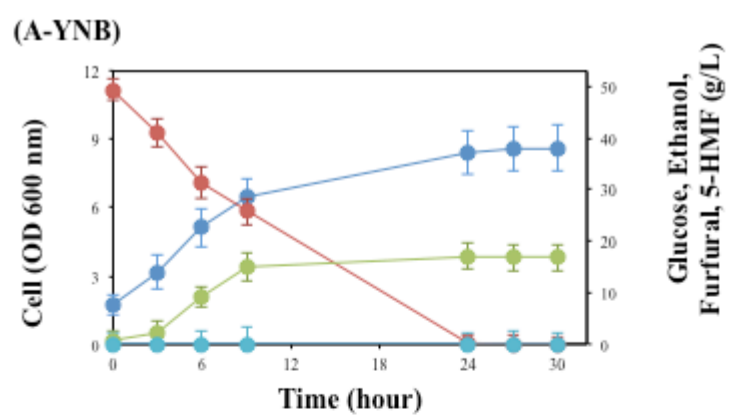

(B-YNBi-1)
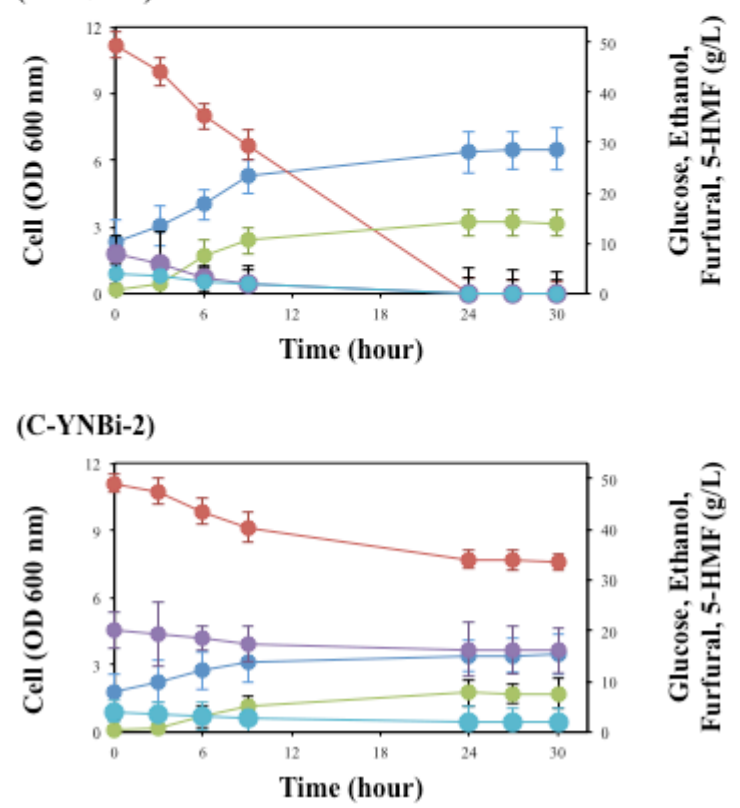

Figure 3. Metabolites change of $C$. parapsilosis InaCCY80 in medium containing 5-HMF. Cell growth ( ); glucose (O); bioethanol (O); furfural $(O)$;5-HMF (O).

\section{Discussion}

Screening of inhibitor-tolerant yeast was performed individually and then tested in furfural and 5-HMF mixtures. The aim of this strategy is to investigate the effects of individual or mixtures of furfural and 5-HMF to the cell growth and ethanol production. Ten strains of the genus Candida were tested for the tolerance in medium containing furfural and 5-HMF as inhibitors. In general, the Candida strains were able to grow and produced bioethanol with varying 
concentrations of furfural and 5-HMF. Yeast of $C$. parapsillosis InaCCY 80 was selected as a potential strain. This strain has the capability to produce bioethanol at a relatively high concentrations of furfural and 5-HMF than other Candida strains tested.

Pandey et al. (2019) reported that Candida strain is one of the yeast groups that can tolerate inhibitor compounds besides Saccharomyces, Kluyveromyces, Candida, Scheffersomyces, Ogatea and Wickerhamomyces. In this study $C$. parapsillosis was more tolerant in furfural and 5-HMF than the other Candida strains.

Furfural is one of the main inhibitors of hemicellulose hydrolysate. This compound has the capability to inhibit the growth of microorganism cells (Taherzadeh et al., 2006) and enzyme activity in the glycolytic pathway (Jönsson et al., 2013). On the other hand, furfural can increase the toxic effect of acetic acid and phenols in furfural toward yeast (Almarsdottir et al., 2012). In Saccharomyces cerevisiae, furfural leads to the accumulation of ROS and cell organelle damage (Allen et al., 2013). Wang et al. (2013) also reported that $C$. tropicalis cell growth and fermentation was inhibited by the presence of furfural.

InaCC80 strain produced ethanol in medium containing furfural and 5-HMF. However, ethanol production in medium containing furfural was higher than in 5-HMF. This means that the InaCC 80 strain is more tolerant of furfural compounds than 5-HMF. This is interesting because some strains are more intolerant to furfural compared to 5HMF. The furfural and 5-HMF are known to cause specific biological effects. Furfural induces the accumulation of reactive oxygen species (ROS) in S. cerevisiae to cause cellular damage includes damage to mitochondria and vacuole membranes, the actin cytoskeleton and nuclear chromatin (Allen et al., 2010) also causes DNA damage, induce DNA mutations in many organisms, reduces growth rates, cell budding, ethanol, and biochemical enzyme activity (Palmqvist and Hahn-Hägerdal, 2000; Modig et al., 2002). Moreover, it affects energy metabolism while changing the TCA and glycolytic fluxes (Horvath et al., 2003). 5HMF is less toxic than furfural, probably because it is hard to penetrate the yeast cell membrane even though in-vivo degradation. Interestingly, we found that the InaCCY80 strain appears capable of detoxifying 5-HMF as its level decreased during the fermentation. This fact indicated that 5-HMF could penetrate the membrane cell of the strain. This inhibitor was completely degraded after 24-h fermentation in the medium $0.2 \mathrm{YNBi}$ +0.8 YNB. The 5-HMF directly inhibits the activities of key enzymes such as aldehyde dehydrogenase, alcohol dehydrogenase, and pyruvate dehydrogenase (Modig et al., 2002). It also generates reactive oxygen species (ROS) and induces cell apoptosis, as well as furfural.

Furfural induces the accumulation of ROS in $S$. cerevisiae to cause cellular damage includes damage to mitochondria and vacuole membranes, the actin cytoskeleton, and nuclear chromatin (Allen et al., 2010) also causes DNA damage, induce DNA mutations in many organisms. The inhibitory effect on various microorganisms including budding yeasts (Almeida et al., 2007; Delgenes et al., 1996) and bacteria (Zaldivar et al., 2000) such as reducing fermentation rate and/or stop growing and enter an extended lag phase (Branberg et al., 2004; Heer and Sauer, 2008). For some tolerance $S$. cerevisiae yeasts, they could convert furfural and 5-HMF to their less reactive alcohol derivatives using $\mathrm{NAD}(\mathrm{P}) \mathrm{H}$ dependent reduction reactions mostly during the lag phase (Almeida et al., 2007).

\section{Acknowledgements}

This study was supported by DIPA National Priority Project of Biorefinery and Biomass for Research Center for Biotechnology, Indonesian Institute of Sciences (LIPI) 2019. AT as the main contributor. AT carried out idea and the experiment. LNK and UP analyzed of samples. AT wrote the manuscript with support from LNK. Y and BP supervised the project. AT as the main contributor. AT planned and carried out the experiment with supported from UP. LNK and UP analyzed of samples. AT wrote the manuscript with support from LNK. AK, Y and $\mathrm{BP}$ supervised the project.

\section{References}

Ahmad, S., Pathak, V. V., Kothari, R., \& Singh, R. P. (2017). Prospects for pretreatment methods of lignocellulosic waste biomass for biogas 
enhancement: opportunities and challenges. Biofuels, 1-20. doi:10.1080/17597269.2017. 13789

Allen, S.A, Clark, W., McCaffery, J., Cai, Z., Lanctot, A., \& Slininger, P.J., et al. (2010). Furfural induces reactive oxygen species accumulation and cellular damage in Saccharomyces cerevisiae. Biotechnol Biofuels. $3(1), 1$.

Almarsdottir, A.R., Sigurbjornsdottir, M.A., \& Orlygsson, J. (2012). Effect of various factors on ethanol yields from lignocellulosic biomass by Thermoanaerobacterium AK17. Biotechnol Bioeng. 109(3), 686-94.

Almeida, J.R.M., Modig, T., Petersson, A., HahnHagerdal, B., Liden, G., \& Grauslund, M. F.G. (2007). Increased tolerance and conversion of inhibitors in lignocellulosic hydrolysates by Saccharomyces cerevisiae. Journal of Chemical Technology and Biotechnology, 82, 340-349.

Ask, M., Bettiga, M., Mapelli, M., \& Olsson, L. (2013). The influence of HMF and furfural on redox-balance and energy-state of xyloseutilizing Saccharomyces cerevisiae. Biotechnology for Biofuels, 6, 22

Baruah, J., Nath, B. K., Sharma, R., Kumar, S., Deka, R. C., Baruah, D. C., \& Kalita, E. (2018). Recent Trends in the Pretreatment of Lignocellulosic Biomass for Value-Added Products. Frontiers in Energy Research, 6. doi:10.3389/fenrg.2018.00141

Branberg, T., Franzenand, C.J., \& Gustafsson, L. (2004). The fermentation performance of nine strains of Saccharomyces cerevisiae in batch and fed-batch cultures in dilute-acid wood hydrolysate. Journal of Bioscience and Bioengineering, 98 (2),122-125.

Chen, H., Liu, J., Chang, X., Chen, D., Xue, Y., Liu, P., ... Han, S. (2017). A review on the pretreatment of lignocellulose for high-value chemicals. Fuel Processing Technology, 160, 196-206. doi:10.1016/j.fuproc.2016.12.007.

Delgenes, J.P., Moletta, R., \& Navarro, J.M., (1996). Effects of lignocellulose degradation products on ethanol fermentations of glucose and xylose by Saccharomyces cerevisiae, Zymomonas mobilis, Pichia stipitis and Candida shehatae. Enzyme Microbial Technology, 19 (3), 220-225.

Gorsich, S.W., Dien, B.S., Nichols, N.N., Slininger, P.J., Liu, Z.L., \& Skory, C.D. (2006). Tolerance to furfural-induced stress is associated with pentose phosphate pathway genes $Z W F 1$, GND1, RPE1, and TKL1 in Saccharomyces cerevisiae. Applied Microbiology and Biotechnology, 71, 339-349.

Greetham, D., Hart, A.J., \& Tucker, G.A. (2016). Presence of low concentrations of acetic acid improves yeast tolerance to hydroxymethylfurfural (HMF) and furfural. Biomass Bioenergy, 85, 53.

Greetham, D., Wimalasena, T., Kerruish, D.W., Brindley, S., Ibbett, R.N., Linforth, R.L., Tucker, G., Phister, T.G., \& Smart, K.A. (2014). Development of a phenotypic assay for characterization of ethanologenic yeast strain sensitivity to inhibitors released from lignocellulosic feedstocks. Journal of Industrial Microbiology and Biotechnology, 41, 931-945.

Greetham, D., Zaky, A.S., \& Du, C. (2019). Exploring the tolerance of marine yeast to inhibitory compounds for improving bioethanol production. Sustainable Energy Fuels, 3, 15451553.

Heer, D., \& Sauer, U. (2008). Identification of furfural as a key toxin in lignocellulosic hydrolysates and evolution of a tolerant yeast strain. Microbial Biotechnology, 1(6), 497-506.

Horvath, S.I., Franzen, C.J., Taherzadeh, M.J., Niklasson, C., \& Liden, G. (2003). Effects of furfural on the respiratory metabolism of Saccharomyces cerevisiae in glucose- limited chemostats. Applied Environmental Microbiology, 69, 4076-4086.

Iwaki, A., Kawai, T., Yamamoto, Y., \& Izawa, S. (2017). Biomass conversion inhibitors furfural and 5-hydroxymethylfurfural induce formation of messenger rnp granules and attenuate translation activity in Saccharomyces cerevisiae. Applied and Environmental Microbiology, 79(5), 1661-1667.

Jeffrey, A., Mertensa, Kellyb, A., \& Hectora, R.E. (2018). Screening for inhibitor tolerant Saccharomyces cerevisiae strains from diverse environments for use as platform strains for production of fuels and chemicals from biomass. Bioresource Technology Reports, 3, 154-161.

Johansson, E., Xiros, C., \& Larsson, C. (2014). Fermentation performance and physiology of two strains of Saccharomyces cerevisiae during growth in high gravity spruce hydrolysate and spent sulphite liquor. BMC Biotechnology, 14, 47.

Jönsson, L.J., \& Martín, C. (2016) Pretreatment of lignocellulose: Formation of inhibitory byproducts and strategies for minimizing their effects. Bioresources Technology, 199, 103112.

Jönsson, L.J., Alriksson, B., \& Nilvebrant, N-O. (2013). Bioconversion of lignocellulose: inhibitors and detoxification. Biotechnol Biofuels, 6(1), 1.

Kahar, P., Riyanti, E.I., Otsuka, H., Matsumoto, H., Kihira, C., Ogino, C., \& Kondo, A. (2017). Challenges of non-flocculating Saccharomyces cerevisiae haploid strain against inhibitory chemical complex for ethanol production. Bioresource Technology, 245, 1436-1446. 
Klein, C.J., Rasmussen, J.J., Rønnow, B., Olsson, L., \& Nielsen, J. (1999). Investigation of the impact of $M I G 1$ and $M I G 2$ on the physiology of Saccharomyces cerevisiae. J. Biotechnol, 68 (23), 197-212.

Kumar A.K., \& Sharma, S. (2017). Recent updates on different methods of pretreatment of lignocellulosic feedstocks: a review. Bioresources Bioprocess, 4, 7. doi: 10.1186/s40643-017-0137-9.

Lia, Y.C., Goua, Z.X., Zhanga, Y., Xiaa, Z.Y., \& Tanga, Y.Q., \& Kida, K. (2017). Inhibitor tolerance of a recombinant flocculating industrial Saccharomyces cerevisiae strain during glucose and xylose co-fermentation. Brazilian journal of microbiology, 48, 791-800.

Liu, Z.L., Slininge, P.J., Dien, B.S., Berhow, M.A., Kurtzman, C.P., \& Gorsich, S.W. (2004). Adaptive response of yeasts to furfural and 5hydroxymethylfurfural and new chemical evidence for HMF conversion to 2,5-bishydroxymethylfuran. Journal of Industrial Microbiology and Biotechnology, 31, 345-352.

Lourencetti, N.M.S., Wolf, I.R., Lacerda, M.P.F., Valente, G.T., Zanelli, C.F., Santoni, M.M., Giannini, M.J.S.M., Enguita, F.J., \& Almeida, A.M.F. (2018). Transcriptional profile of a bioethanol production contaminant Candida tropicalis. AMB Express, 8, 166.

Modig, T., Liden, G., \& Taherzadeh, M.J. (2002). Inhibition effects of furfural on alcohol dehydrogenase, aldehyde dehydrogenase and pyruvate dehydrogenase. Biochem Journal, 363, 769-776.

Modig, T., Liden, G., Taherzadeh, M.J. (2002). Inhibition effects of furfural on alcohol dehydrogenase, aldehyde dehydrogenase and pyruvate dehydrogenase. Biochemical Journal, 363, 769-776.

Narayanan, V., Schelin, J., Grauslund, M.G., van Niel, E.W.J., \& Carlquist, M. (2017). Increased lignocellulosic inhibitor tolerance of Saccharomyces cerevisiae cell populations in early stationary phase. Biotechnology Biofuels, 10,114

Nutawan, Y., P. Phuriphipat, P., Treyawutthiwat \& Eshtiaghi, M.N. (2010). Bioethanol production from rice straw, Energy Research Journal, 1(1), 26-31.

Ohta, E., Nakayama, Y., Mukai, Y., Bamba, T., \& Fukusaki, E. (2016). Metabolomic approach for improving ethanol stress tolerance in Saccharomyces cerevisiae. Journal of Bioscience and Bioengineering, 121(4), 399405. doi: 10.1016/j.jbiosc.2015.08.006.

Palmqvist, E., \& Hahn-Hägerdal, B., (2000). Fermentation of lignocellulosic hydrolysates. II: inhibitors and mechanisms of inhibition. Bioresouresorces Technology, 74, 25-33.
Pandey, A.K., Kumar, M., Kumari, S., Kumari, P., Yususf, F., Jakeer, S., Naz, S., Chandna, P., Bhatnagar, I., \& Gaur, N.A. (2019). Evaluation of divergent yeast genera for fermentationassociated stresses and identification of a robust sugarcane distillery waste isolate Saccharomyces cerevisiae NGY10 for lignocellulosic ethanol production in SHF and SSF. Biotechnology for Biofuels, 12, 40. doi.org/10.1186/s13068-019-1379-x.

Parawira, W., \& Tekere, M., 2011. Biotechnological strategies to overcome inhibitors in lignocellulose hydrolysates for ethanol production. Critical Review Biotechnology, 31 (1), 20-31.

Park, S.E., Koo, H.M., Park, Y.K., Park, J.C., Lee, O.K., Park, Y.C., \& Seo, J.H. (2011). Expression of aldehyde dehydrogenase 6 reduces inhibitory effect of furan derivatives on cell growth and ethanol production in Saccharomyces cerevisiae. Bioresource Technology, 102, 6033-6038.

Purwadi, R., Brandberg, T., \& Taherzadeh, M.J. (2007). A possible industrial solution to ferment lignocellulosic hydrolyzate to ethanol: continuous cultivation with flocculating yeast. International Journal Molecular Science, 8 (9), 920-932.

Sarks, C., Dale, B.E., \& Balan, V. (2018). Watersoluble phenolic compounds produced from extractive ammonia pretreatment exerted binary inhibitory effects on yeast fermentation using synthetic hydrolysate. PLOS ONE. doi:10.1371/journal.pone.0194012

Steinbach, D., Kruse, A. \& Sauer, J. (2017). Pretreatment technologies of lignocellulosic biomass in water in view of furfural and 5hydroxymethylfurfural production-a review. Biomass Conversion and Biorefinery, 7, 27.

Taherzadeh, M., Gustafsson, L., Niklasson, C., \& Lidén, G. (2006). Physiological effects of 5hydroxymethylfurfural on Saccharomyces cerevisiae. Appl Microbiol Biotechnol, 53(6), 701-708.

Unrean, P., Gätgens, J., Klein, B., Noack, S., \& Champreda, V. (2018). Elucidating cellular mechanisms of Saccharomyces cerevisiae tolerant to combined lignocellulosic-derived inhibitors using high-throughput phenotyping and multiomics analyses. FEMS Yeast Research, 1(18), 8. doi: 10.1093/femsyr/foy106.

Valdivia, M., Galan, J.L., Laffarga, J., \& Ramos, J.L. (2016). Biofuels 2020: Biorefineries based on lignocellulosic materials. Microbial Biotechnology, 9, 585-594.

Wang, L., Tang, P., Fan, X., \& Yuan, Q. (2013). Effect of selected aldehydes found in the corncob hemicellulose hydrolysate on the growth and xylitol fermenta- tion of Candida 
tropicalis. Biotechnology Programme. 29(5), 1181-9.

Xue, S., Jones, A.D., Sousa, L., Piotrowski, J., Jin, M., Satari, B., Karimi, K., \& Kumar, R. (2019). Cellulose solvents-based pretreatment for enhanced second-generation biofuels production: A Review. Sustainable Energy \& Fuels. doi:10.1039/c8se00287h

Zaky, A., Pensupa, N., Eiroa, A.A., Tucker, G.A., \& Du, C.J. (2017). A new HPLC method for simultaneously measuring chloride, sugars, organic acids and alcohols in food samples. Food Compos Analytic, 56, 8. doi: 10.1016/j.jfca.2016.12.010.

Zaky, A.S., Greetham, D., Tucker, G.A., \& Du, C. (2018). The establishment of a marine focused biorefinery for bioethanol production using seawater and a novel marine yeast strain. Scientific Reports, 8, 12127. doi:10.1038/s41598-018-30660-x.

Zaldivar, J., Martinez, A., \& Ingram, L.O. (2000). Effect of alcohol compounds found in hemicellulose hydrolysate on the growth and fermentation of ethanologenic Escherichia coli. Biotechnol Bioeng, 68(5), 524-30.

Zhang, J., Zhang, W.X., Wu, Z.Y., Yang, J., Liu, Y.H., Zhong, X., \& Deng, Y. (2013). A comparison of different dilute solution explosions pretreatment for conversion of distillers grains into ethanol. Preparative Biochemistry Biotechnology, 43:1-21. 